\title{
Epidemiologic profile and quality of life of patients treated for oral cancer in Juiz de Fora, Minas Gerais, Brazil
}

\author{
Rodolfo-Ribeiro de Jesus ${ }^{1}$ Tufi-Neder Meyer ${ }^{2}$ Isabel-Cristina-Gonçalves Leite ${ }^{3}$ Alessandro-Antonio-Costa \\ Pereira ${ }^{4}$ Mônica-Costa Armond ${ }^{5}$
}

\author{
${ }^{1}$ M.Sc, Oral Diagnosis, Vale do Rio Verde University, Três Corações (MG), Brasil \\ ${ }^{2} \mathrm{Ph} . \mathrm{D}$, Professor, M.Sc. Course on Oral Diagnosis, Vale do Rio Verde University \\ ${ }^{3}$ Ph.D, Professor, Medicine College, Federal University of Juiz de Fora (MG), Brasil \\ ${ }^{4}$ Ph.D, Professor, M.Sc. Course on Oral Diagnosis, Vale do Rio Verde University \\ ${ }^{5}$ Ph.D, Professor, M.Sc. Course on Oral Diagnosis, Vale do Rio Verde University
}

Correspondence:

Rua Des.Alberto Luz, 129, Centro

37410-000 Três Corações

MG-Brasil

tufi@uai.com.br

Received: $27 / 02 / 2009$

Accepted: 30/07/2009

de Jesus RR, Meyer TN, Leite IC, Pereira AA, Armond MC. Epidemiologic profile and quality of life of patients treated for oral cancer in Juiz de Fora, Minas Gerais, Brazil. Med Oral Patol Oral Cir Bucal. 2010 Jan $1 ; 15$ (1):e20-4.

http://www.medicinaoral.com/medoralfree01/v15i1/medoralv15ilp20.pdf

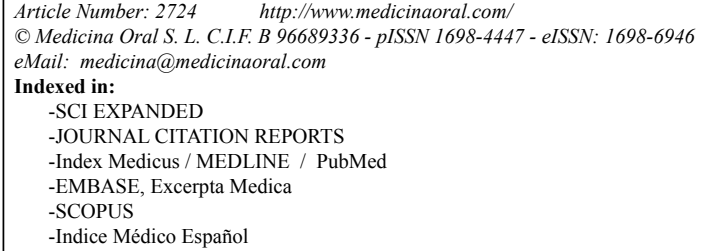

\begin{abstract}
Objectives: To assess the quality of life of patients treated for oral cancer, analyzing their physical, social/family, functional and emotional well-being; to identify socioeconomic and clinical functional variables that may potentially influence their quality of life; to describe the patients' epidemiologic profile (sex and age) and tumor features (histopathology, anatomical location and stage); to identify the frequency of risk factors associated with the malignancy. Study design: Observational cross-sectional study-case series study undertaken in 2 cancer treatment institutions in Juiz de Fora, Minas Gerais, Brazil, between 2000 and 2007. Results: Of the 88 registered oral cancer patients, 16 were selected for the study sample. The majority of the study sample (87\%) included males, with a mean age of 57.06 years; $43.8 \%$ were retired; $50 \%$ had not completed elementary education. Most (56.3\%) had a monthly income of less than the minimum wage. Most (83.7\%) smoked before cancer diagnosis and $43.8 \%$ from this sample continued to smoke after treatment. In addition, those who drank alcohol before treatment continued drinking (31.3\%). The tongue was the predominant anatomic site $(37.5 \%)$. The patients' quality of life score was fair; the best result was for emotional well-being. Conclusions: Despite the limitations imposed by low survival, it was possible to evaluate the quality of life of these patients. Patients having a family income higher than the minimum monthly wage scored significantly better in final indexes FACT-G and FACT-HN than those with a lower income.
\end{abstract}

Key words: Cancer, oral cancer, quality of life, epidemiology. 


\section{Introduction}

Cancer treatment is complex and involves experienced and skilled specialists working in adequate facilities to offer diagnosis, staging, treatment and physical, psychological and social rehabilitation. The main aims are to lengthen patients' survival and improve their quality of life. Although cure can be achieved in as many as $60 \%$ of the cases, this does not necessarily mean improvement of the quality of life, the latter being a great challenge for oncology (1).

Questionnaires on quality of life in cancer are successfully used to assess health status, therapy efficacy and patients functional status and well-being (2).

Because such assessments are not routinely done in the country, there is a paucity of Brazilian studies about this topic. There are no records of such studies applied to oral cancer in Juiz de Fora, Minas Gerais (MG), Brazil, a city with over 500,000 inhabitants.

This study aimed to assess the quality of life, concerning the physical, social/family, functional and emotional well-being of a series of patients with oral cancer undergoing treatment in Juiz de Fora. The Functional Assessment of Cancer Therapy-Head and Neck (FACT$\mathrm{HN}$ ) questionnaire, validated for Brazil (3), was used. There were also three secondary aims: to identify variables (socioeconomic, clinical functional) potentially influencing the quality of life in this series; to describe the epidemiologic profile of the series regarding the distribution of sex, age range and tumor patterns (histopathology, anatomical location and stage); to identify the frequency of risk factors associated with cancer etiology in the study group.

\section{Material and Methods}

Observational cross-sectional study - case series study undertaken in the University Hospital of the Federal University of Juiz de Fora and in the Female Association for The Prevention and Treatment of Cancer in Juiz de Fora (ASCOMCER) Hospital.

The project was approved by the Committee of Ethics on Research of the Federal University of Juiz de Fora (Resolution 366/2007) and complies with the Guidelines on Human Research (resolution 196 from 10 October, 1996) issued by the Brazilian National Health Council (Ministry of Health).

16 patients satisfied the inclusion criteria: diagnosis of oral cancer in the period 2000-2007 in Juiz de Fora; age over 18 years; absence of neurological or cognitive deficits impairing comprehension and full participation; any schooling level; primary tumor located in the oral region; at least 1-year survival.

We analyzed medical files of patients from the aforementioned hospitals who met the inclusion criteria. Personal data, socioeconomic and demographic (age, sex, income, schooling) profiles, clinical features (malignan- cy site, type, TNM classification and treatment) and associated risk factors (smoking, alcohol intake, hygiene habits) were identified. 88 patients meeting the criteria were selected. Of these, 48 were initially considered to be fit for the study. Yet, due to deaths, wrong addresses and individual refusals, the final sample was composed of 16 patients.

Before the interview each patient gave an informed consent. The interviews were scheduled according to patient availability, and were conducted either in the hospital or in the patient's home. The interviewer (the first author in all cases) read the questions along with the interviewee, any doubt being then clarified.

A version in Portuguese of the Functional Assessment of Cancer Therapy - Head and Neck (FACT-HN version 4, 2003) questionnaire, structurally adapted in accordance with the Functional Assessment of Chronic Illness Therapy (FACIT) was used. Quality of life was the outcome variable. Five domains were assessed: physical well-being (PWB), social and family well-being (SFWB), emotional well-being (EWB), functional well-being (FWB) and additional worries regarding head and neck cancer (HNCAW). Data analysis was made for each domain and three global indices: TOI, involving PWB, FWB and HNCAW; FACT-G, involving PWB, SFWB, EWB and FWB; and FACT-HN, with the five domains. The five-point $(0-4)$ Lickert scale was used. Final scores for each domain and the global indices were obtained. The higher the score the better the quality of life was considered. Minimum and maximum values, mean, median and standard deviation, percentage of patients scoring within the upper quartile of maximum score for all domains of the questionnaire and the global final indices were obtained.

The Statistical Product and Service Solutions (SPSS) for Windows, version 15.0, was used to measure central tendencies (mean, median) and dispersion (standard deviation) of the quantitative variables and the absolute and relative frequencies of the qualitative variables. For comparison of the scores of quality of life according to the sociodemographic, economic and clinical functional variables, Student's t test was used for two independent samples and variance analysis (ANOVA) for more than two samples. The results were considered statistically significant when $\mathrm{p} \leq 0.05$.

\section{Results}

$85.7 \%$ of the patients were male. Age ranged from 34 to 80 years (median 57.06 years). $75 \%$ were white, and the same percentage was married. $50 \%$ had not finished fundamental education. The most frequent profession was salesperson $(31.25 \%)$, followed by driver $(6.25 \%)$ and construction worker $(6.25 \%)$. The two women of the sample were salesperson and seamstress. $43.8 \%$ were retired (two due to disability and two who had reached retirement age); one was unemployed because of treat- 
ment constraints, one was self-employed and four were working. $56.3 \%$ had a family income below or equal to the monthly minimum wage, $31.3 \%$ received up to the equivalent of three minimum wages and $12.5 \%$ received from three to ten minimum wages. $50 \%$ came from a household with another or two other people while $43.8 \%$ lived with three to four other people.

Of the 16 patients, one (6.3\%) had never smoked, eight $(50 \%)$ had smoked up to treatment onset and seven $(43.8 \%)$ were previous smokers who continued to smoke after treatment onset. As for alcohol intake, one (6.3\%) had never drunk alcohol, ten $(62.5 \%)$ had drunk up to treatment onset and five (31.3\%) carried on drinking after treatment onset. Regardless of the occupation, nine (56.3\%) reported sun exposure at work. $68.8 \%$ used dentures. Dental floss use was reported by $18.7 \%$.

The tongue was the predominant anatomical location $(37.5 \%)$, followed by the gums $(25 \%)$. Squamous cell carcinoma was the predominant histology (87.5\%). Most $(68.8 \%)$ were stages $\mathrm{T} 1$ and $\mathrm{T} 2$ at diagnosis. $68.9 \%$ were $\mathrm{N} 1, \mathrm{~N} 2$ or N3. Two (12.5\%) had distant metastases (M1). $43.7 \%$ underwent surgery, $31.3 \%$ received surgery plus radiotherapy and $25 \%$ received radiotherapy plus chemotherapy.

In general, quality of life was estimated as regular, with $25 \%$ to $43.7 \%$ scoring within the higher quartile of the maximum score for each domain or sub-score (PWB, SFWB, EWB, FWB and HNCAW). For the final indices (FACT-G and FACT-HN) the percentage was between $18.7 \%$ and $31.2 \%$ (Table 1 ).

Taking the means of the scores for the 5 domains into account, and calculating the difference between these means and the maximum possible scores for each domain, the best result was for EWB followed in decreasing order by PWB, SFWB, FWB and HNCAW (Fig. 1).
As for the sociodemographic features, the differences for the TOI, FACT-G and FACT-HN indices indicated the best scores for patients who had finished secondary school $(p=0.028 ; p=0.034 ; p=0.026$, respectively). As for marital status and declared color, the differences were not statistically significant.

Concerning the socioeconomic features, the differences for the TOI, FACT-G and FACT-HN indices indicated better scores for patients with family income above the minimum wage for FACT-G $(\mathrm{p}=0.036)$, but not for TOI and FACT-HN $(\mathrm{p}=0.168$ and $\mathrm{p}=0.058$, respectively). There were no statistically significant differences in the results of comparisons of the TOI, FACT-G and FACT$\mathrm{HN}$ indices $(\mathrm{p}=0.411 ; \mathrm{p}=0.185 ; \mathrm{p}=0.268)$ between those who were salespeople and those with other occupations. For the TOI, FACT-G and FACT-HN indices, the results concerning smoking, alcohol intake, sun exposure at work and use of dentures did not show statistically significant differences. As for dental floss use, the best scores for those indices belonged to patients who used dental floss $(\mathrm{p}=0.016 ; \mathrm{p}=0.038 ; \mathrm{p}=0.014)$.

No statistically significant differences were observed pertaining $\mathrm{T}$ stage, tumor site, histological type, metastases and therapy modality.

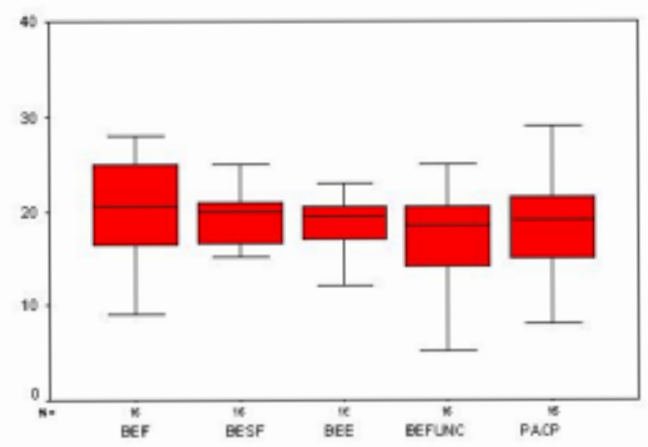

Fig. 1. Weighted mean for the FACT-HN domains in decreasing order.

Table 1. Descriptive statistics of FACT-HN. Juiz de Fora, 2008.

\begin{tabular}{|l|c|c|c|c|c|}
\hline $\begin{array}{l}\text { Variables (maximum } \\
\text { possible score) }\end{array}$ & Minimum & Maximum & Mean & $\begin{array}{c}\text { Standard } \\
\text { deviation }\end{array}$ & $\begin{array}{c}\text { \% of patients in the } \\
\text { score higher quartile }\end{array}$ \\
\hline PWB (28) & 9 & 28 & 20.3 & 5.4 & 31.2 \\
\hline SFWB (28) & 5.8 & 25 & 18.6 & 5.0 & 37.5 \\
\hline EWB (24) & 7 & 23 & 18.3 & 3.9 & 25 \\
\hline FWB (28) & 5 & 25 & 17.3 & 5.1 & 25 \\
\hline HNCAW (36) & 8 & 29 & 19.2 & 5.6 & 43.7 \\
\hline TOI (92) & 34 & 80 & 56.6 & 13.4 & 31.2 \\
\hline FACT-G (108) & 26,8 & 97 & 74.4 & 16.0 & 18.7 \\
\hline FACT-HN (144) & 48.8 & 125.0 & 93.6 & 18.6 & 31.2 \\
\hline
\end{tabular}

Key:FWB-physical well-being, SFWB-social family well-being, EWB-emotional well-being, FWBfunctional well-being, $\mathrm{HNCAW}$-head and neck canceradditional worries, $\mathrm{TOI}=\mathrm{PWB}+\mathrm{FWB}+\mathrm{HNCAW}$, FACT-G $=$ PWB+SFWB+EWB+FWB, FACT-HN $=$ PWB+SFWB+EWB+FWB+HNCAW. 


\section{Discussion}

Regardless of age range, oral cancer predominantly affects men (4-15), a finding confirmed in this study, in which $85.7 \%$ were male. Occurrence is more frequent in old age $(6,9,10,16,17)$. The mean age in this study $(57.06$ years, with $43.8 \%$ retired) is in agreement with literature data $(4,5,12,14)$.

Low schooling was found, with $50 \%$ of the patients with incomplete fundamental education. Differences for the final TOI (69.0), FACT-G (88.7) and FACT-HN (111.0) indices showed better scores for those with secondary education ( $p=0.028 ; p=0.034 ; p=0.026$, respectively). In a study relating survival free of disease and education, Yeole et al. (15) reported the worst percentages for those illiterate.

Most patients (56.3\%) earned up to 1 minimum wage a month. Fang et al. (13) reported that most men in their sample belonged to disadvantaged social classes, and that more than half had fewer than six years of formal education. In the final indices related to socioeconomic features, the best scores were of those with family income over 1 minimum age for the final FACT-G index $(p=0.036)$, with a mean of 83.7, and for the final FACT-HN index ( $\mathrm{p}=0.058$, respectively), with a mean of 103.5.

The main histological type was squamous cell carcinoma (87.5\%), in accordance with literature data. The tongue was the predominant anatomical location $(37.5 \%)$, also in accordance with recent studies $(4,6,8-10,12,17,18)$. Some studies on oral cancer $(2,3,5,14)$ have reported regularly reduced scores for the global status of quality of life for up to 5 years after treatment, chiefly when there is combination therapy (surgery plus radiotherapy, with or without chemotherapy). In this study most patients (56.3\%) received combination therapy, there being no statistically significant differences in the final TOI $(\mathrm{p}=0.933)$, FACT-G (0.673) and FACT-HN $(\mathrm{p}=0.820)$ indices as for measurement of quality of life.

Marital status, declared color, occupation, smoking, alcohol intake, sun exposure and use of dentures did not determine statistically significant differences in the results of this study. The same happened when stage, tumor site, histological type, metastases and therapy modality were considered. This is at least partially similar to literature data. Smith et al. (19) used the FACT-G and FACT-HN, UW-QOL and PSS-HN tools to assess the functional status of oral cancer survivors who had undergone deformity reconstruction. These authors also found tumor stage and location not to be statistically significant in the assessment of quality of life.

Patients who used dental floss scored better in the final indices ( $p=0.016 ; p=0.038 ; p=0.014)$. Dental floss use may be a practice linked to better social and educational levels, as it is a preventive strategy generally associated with better understanding (more commonly found in those from higher social levels and/or better access to health promotion services). This could account for the higher scores found.

The limited number of 16 patients in our series is a statistical drawback. Some inconsistencies regarding the biological plausibility of some findings (e.g., patients with metastases scoring higher in FACT-G) should not be considered in the analysis of quality of life, as because of the small number of patients there was no statistical significance, the finding being written off to chance.

These limitations notwithstanding, this study outlines the epidemiologic pattern and quality of life profile of patients with oral cancer in Juiz de Fora, contributing to the limited amount of information in this field. A study with a larger sample will be more scientifically sound and will be a more faithful picture of the real situation. Assessment of the quality of life of patients who have undergone long and painstaking treatment for such a serious condition is an essential component of the answer to a question: does the professional approach to these patients provide not only good cost/survival rates but also desirable quality of life?.

\section{Conclusions}

The FACT-G and FACT-HN tools were adequately applied to head and neck cancer patients in Juiz de Fora, MG, allowing for the assessment (with limitations) of their quality of life to be made. Better results were in the emotional well-being domain.

The epidemiologic profile of the study series did not differ from literature data. The factors that better influenced the indices were dental floss use and better schooling (TOI, FACT-G and FACT-HN) and family income above 1 minimum age/month (FACT-G and FACT-HN). The risk factors found did not differ from literature data.

\section{References}

11. Kowalski LP, Carvalho AL. Natural history of untreated head and neck cancer. Eur J Cancer. 2000;36:1032-7.

2. Andrade FP, Antunes JL, Durazzo MD. Evaluation of the quality of life of patients with oral cancer in Brazil. Braz Oral Res. 2006;20:290-6.

3. Vartanian JG, Carvalho AL, Yueh B, Priante AV, De Melo RL, Correia LM, et al. Long-term quality-of-life evaluation after head and neck cancer treatment in a developing country. Arch Otolaryngol Head Neck Surg. 2004;130:1209-13.

4. Brandizzi D, Gandolfo M, Velazco ML, Cabrini RL, Lanfranchi HE. Clinical features and evolution of oral cancer: A study of 274 cases in Buenos Aires, Argentina. Med Oral Patol Oral Cir Bucal. 2008;13:E544-8.

5. Gurney TA, Eisele DW, Orloff LA, Wang SJ. Predictors of quality of life after treatment for oral cavity and oropharyngeal carcinoma. Otolaryngol Head Neck Surg. 2008;139:262-7.

6. Hirota SK, Braga FP, Penha SS, Sugaya NN, Migliari DA. Risk factors for oral squamous cell carcinoma in young and older Brazilian patients: a comparative analysis. Med Oral Patol Oral Cir Bucal. 2008;13:E227-31. 
7. Rogers SN, Brown JS, Woolgar JA, Lowe D, Magennis P, Shaw RJ, et al. Survival following primary surgery for oral cancer. Oral Oncol. 2009;45:201-11.

8. Yoshimura R, Shibuya H, Miura M, Watanabe H, Ayukawa F, Hayashi K, et al. Quality of life of oral cancer patients after lowdose-rate interstitial brachytherapy. Int J Radiat Oncol Biol Phys. 2009;73:772-8.

9. Garavello W, Spreafico R, Gaini RM. Oral tongue cancer in young patients: a matched analysis. Oral Oncol. 2007;43:894-7.

10. Lam L, Logan RM, Luke C, Rees GL. Retrospective study of survival and treatment pattern in a cohort of patients with oral and oropharyngeal tongue cancers from 1987 to 2004. Oral Oncol. 2007;43:150-8.

11. Ghoshal S, Mallick I, Panda N, Sharma SC. Carcinoma of the buccal mucosa: analysis of clinical presentation, outcome and prognostic factors. Oral Oncol. 2006;42:533-9.

12. Koo BS, Lim YC, Lee JS, Choi EC. Recurrence and salvage treatment of squamous cell carcinoma of the oral cavity. Oral Oncol. 2006;42:789-94.

13. Fang FM, Tsai WL, Chien CY, Chiu HC, Wang CJ. Health-related quality of life outcome for oral cancer survivors after surgery and postoperative radiotherapy. Jpn J Clin Oncol. 2004;34:641-6.
14. Kessler PA, Bloch-Birkholz A, Leher A, Neukam FW, Wiltfang J. Evaluation of quality of life of patients with oral squamous cell carcinoma. Comparison of two treatment protocols in a prospective study. Radiother Oncol. 2004;70:275-82.

15. Yeole BB, Ramanakumar AV, Sankaranarayanan R. Survival from oral cancer in Mumbai (Bombay), India. Cancer Causes Control. 2003;14:945-52.

16. Warnakulasuriya S, Mak V, Möller H. Oral cancer survival in young people in South East England. Oral Oncol. 2007;43:982-6.

17. Siriwardena BS, Tilakaratne A, Amaratunga EA, Tilakaratne WM. Demographic, aetiological and survival differences of oral squamous cell carcinoma in the young and the old in Sri Lanka. Oral Oncol. 2006;42:831-6.

18. Brown JS, Rogers SN, Lowe D. A comparison of tongue and soft palate squamous cell carcinoma treated by primary surgery in terms of survival and quality of life outcomes. Int J Oral Maxillofac Surg. 2006;35:208-14

19. Smith GI, Yeo D, Clark J, Choy ET, Gao K, Oates J, et al. Measures of health-related quality of life and functional status in survivors of oral cavity cancer who have had defects reconstructed with radial forearm free flaps. Br J Oral Maxillofac Surg. 2006;44:187-92. 